\title{
Development of a Capability Maturity Model for the Establishment of Children's Nursing Training Programmes in Southern and Eastern Africa
}

\section{Natasha North ( $\sim$ natasha.north@uct.ac.za )}

University of Cape Town Department of Paediatrics and Child Health https://orcid.org/0000-00015317-8919

\section{Minette Coetzee}

University of Cape Town Institute of Child Health: University of Cape Town Department of Paediatrics and Child Health

\section{Research}

Keywords: health workforce, nursing, paediatrics, child, regulation, education, training, stakeholders

Posted Date: January 15th, 2021

DOI: https://doi.org/10.21203/rs.3.rs-145361/v1

License: (a) (i) This work is licensed under a Creative Commons Attribution 4.0 International License. Read Full License

Version of Record: A version of this preprint was published at Evaluation and Program Planning on February 1st, 2022. See the published version at https://doi.org/10.1016/j.evalprogplan.2022.102061. 


\section{Abstract}

Background: Developing high-quality and sustainable training programmes to meet the increasing demand for specialist children's nurses in African countries requires collaborative efforts by multiple stakeholders, systems and organisational tiers. This is made more challenging in the absence of a comprehensive framework for specialist nursing educational programme development. This project set out to develop a Capability Maturity Model in order to systematically describe the essential capacity required to establish a new specialist children's nursing education programme in an African context.

Methods: Previous Capability Maturity Models developed in the fields of nursing regulation and human resources for health information systems were used to guide the process of development. A six-stage process was followed to: identify necessary supportive conditions; specify levels of process maturity; develop domains; characterise levels of capability; consult with stakeholders; and finalise the model.

Results: The process resulted in the identification of set of five step-wise progressions for each of five stakeholder activity domains, and the creation of a comprehensive Capability Maturity Model describing five levels of process maturity in relation to education, clinical and regulatory systems, human resources for health systems, and requirements related to overall stakeholder collaboration. Stakeholder consultation confirmed the accuracy and applicability of the model.

Conclusions: The model successfully makes visible the wide range of regulatory and associated processes involved in developing a new educational programme for specialist nurses, including educational standards, quality assurance, scopes of practice, and systems for licensing and registering specialist children's nurses. Stakeholders will be able to sue the model as a map to identify where they are in the process, and establish the resources and actions needed to make further progress.

\section{Background}

Appropriate education programmes are necessary to ensure an adequate supply of specialist nurses to meet the urgent demand across health systems worldwide. ${ }^{1}$ Specialist nurses are equipped with educational preparation and extensive clinical experience in a specialty beyond that of a generalist nurse, enabling them to perform identified activities in line with their personal level of proficiency and scope of practice. ${ }^{2}$

A growing number of African countries are prioritising the development of the specialist children's nursing workforce, recognising the potential for skilled children's nurses to contribute to improved health outcomes for children. ${ }^{3}$ There are concerns about the sustainability of some health workforce development and training initiatives in low- and middle-income countries. ${ }^{4}$ It is increasingly recognised that building sustainable capacity in specialist nursing education requires the development of supportive conditions created through policies, frameworks and strategies, requiring collaborative efforts by multiple stakeholders. ${ }^{2}$ Regulatory systems and processes are central to this endeavour, but regulators and other 
stakeholders must work together to achieve the shared objective of high-quality sustainable training provision aligned to the needs, priorities, resources, legislative and regulatory frameworks of a specific health system. This requires a high degree of integration and stakeholder collaboration ${ }^{5}$ which may be difficult to achieve when stakeholders have an incomplete view of the wider system or are unfamiliar with the operational considerations of other sectors and institutions.

The necessary supportive conditions for this endeavour can be described comprehensively and systematically in the form of a Capability Maturity Model. A Capability Maturity Model depicts the organisational processes, practices and behaviours (the supportive conditions) that reliably and sustainably produce required outcomes. ${ }^{6}$ These supportive conditions are commonly represented as a three- to six-stage stepwise progression spanning the earliest stages of a process through to achieving the desired level of development or maturity. ${ }^{7}$ The intention is that by identifying critical success factors and enabling objective measurement, institutions will be able to assess their capacity, processes, and structures and engage in a process of continuous improvement. ${ }^{8}$

The USAID-funded Measure Evaluation project has described six instances of applying the capability maturity model approach to strengthen health data systems. ${ }^{9} \mathrm{~A}$ staged capability maturity model approach has also been used successfully to support and measure progress towards health profession regulation strengthening in Africa through the development of a Regulatory Function Framework used to evaluate progress in key regulatory functions. ${ }^{10,11}$

Since 2008 The Harry Crossley Children's Nursing Development Unit (CNDU) at the University of Cape Town has assisted colleagues at seven schools of nursing in six African countries (Botswana, Kenya, Malawi, Namibia, Zambia and Zimbabwe) to establish nine new children's nursing training programmes. ${ }^{12}$ In addition CNDU has established two entirely new children's nursing educational programmes and re-established a third programme in South Africa. These experiences have generated rich process learning which to date has not been formally recorded. In 2020 CNDU was asked by the Vitol Foundation to capture this learning in the form of a Capability Maturity Model, which we believe represents the first instance of applying this approach to the development of specialist nursing education programmes. In taking forwards this work, we explicitly adopted an assets-based approach which makes visible and values the skills, knowledge, potential and resources in a system and among stakeholder groups, ${ }^{13}$ consistent with principles of Afrocentric educational practice and research design.

\section{Methods}

\section{Aim and objectives}

In undertaking this project, our aim was to utilise learning gained through experience to develop a capability maturity model which describes the essential capacity required to establish a new children's nursing education programme. 
Objectives were to:

- Identify the full range of supportive conditions that must be in place to enable the development of new children's nursing education programmes;

- Describe the key functions and responsibilities of the major stakeholder groups who need to contribute to the development of new children's nursing education programmes; and

- Access collective expertise by consulting with the community of children's nursing education practitioners in southern and eastern Africa.

Our intention was that the resulting capability maturity model could enable stakeholders to assess their current level of capability maturity in relation to each domain, stimulating reflection and process improvements, ultimately supporting the development of high-quality sustainable training provision for children's nursing, primarily in Africa.

\section{Development Process}

We followed methods described by McCarthy et al. ${ }^{10}$ and Measure Evaluation Systems ${ }^{9}$. The process of developing the capability maturity model involved six main phases of activity, as follows:

i. Identification of relevant processes, practices and behaviours;

ii. Specification of the levels of process maturity;

iii. Development of domains with definitions;

iv. Characterisation of different levels of capability;

v. Consultation with stakeholders; and

vi. Incorporation of consultation responses and finalisation of the model

The authors are two nursing academics who worked together to complete all stages of the process. A monitoring and evaluation specialist external to the programme provided additional facilitation of the process. The process was completed between July and October 2020. A record was maintained of the process followed, together with reflections on the process. The stages of development are reported below in such a way that others could reproduce the process.

\section{i) Identification of relevant processes, practices and behaviours}

In order to identify the organisational processes, practices and behaviours (the supportive conditions) that contribute to the establishment of a new children's nursing education programme, we began with a review of published records and accounts of relevant new training programme development (e.g. Coetzee et al. ${ }^{14}$ ) and unpublished programme documentation including travel and seminar reports, annual reports and conference presentations. This was intended to ensure that the model would be grounded in the collective experience and knowledge of establishing new children's nursing educational programmes within the southern and eastern African region. 


\section{ii) Specification of the levels of process maturity}

The processes, practices and behaviours identified through review of programme documentation were used to develop macro-descriptions for five levels of process maturity (see Table 1), guided by completion of the statement: 'A successful sustainable children's nursing education programme has/is...?'. We found it helpful to begin at the end by describing full maturity, before working backwards.

The macro-descriptions of the levels were intended to describe all relevant aspects of the process at high level. The intention was that the macro-descriptors should contain sufficient information about the 'whole picture' so that the essential elements would be visible to any stakeholder as part of an integrated process. Information contained in the macro-descriptors related to conditions that enable necessary actions/progress, guided by the prompt: 'What needs to be in place to enable all actors to do their work?'.

\section{iii) Development of domains with definitions}

The review of programme documentation described above included a framework to guide stakeholder collaboration which was developed at a colloquium of South African stakeholders in children's nursing education (2012) and has been routinely used by CNDU as part of new educational programme development activities with teams in other African countries subsequently. ${ }^{15}$ This framework was used to structure the domains of the Capability Maturity Model (see Table 1) in order to meet the need to describe processes, practices and behaviours at both individual and organisational tiers, as noted above.

We identified definitions for each domain from the literature and recorded these to reduce ambiguity and enable consistent application. As we identified definitions, we found this assisted us in clarifying the steps in a process from nascent to established. For example, applying the definition developed by Deverka et al. ${ }^{16}$ helped us identify a progessive description of stakeholder collaboration as detailed in Table 1.

Table 1: Domains and definitions 


\begin{tabular}{|c|c|}
\hline Domain & Domain definition \\
\hline $\begin{array}{l}\text { Education } \\
\text { system } \\
\text { capacity }\end{array}$ & $\begin{array}{l}\text { The perceived abilities, skills, and expertise of leaders, teachers, faculties, and } \\
\text { staff in education institutions to execute or accomplish something specific, such } \\
\text { as leading a school-improvement effort or teaching more effectively. }{ }^{17}\end{array}$ \\
\hline $\begin{array}{l}\text { Clinical } \\
\text { system } \\
\text { capacity }\end{array}$ & $\begin{array}{l}\text { A capacitated clinical system able to support the establishment of new training } \\
\text { programmes has adequate appropriately trained and motivated health workers, a } \\
\text { well-maintained infrastructure, and a reliable supply of medicines and } \\
\text { technologies, backed by adequate funding, strong health plans and evidence- } \\
\text { based policies. }\end{array}$ \\
\hline $\begin{array}{l}\text { Human } \\
\text { resources for } \\
\text { health } \\
\text { information } \\
\text { and planning } \\
\text { capacity } \\
\text { (HRH) }\end{array}$ & $\begin{array}{l}\text { The concept of Human Resources for Health comprises planned endeavours } \\
\text { intended to increase the capacity of the health workforce in order to optimise } \\
\text { health system functioning and ultimately enhance health. } \\
\text { The health workforce is defined by the WHO as "all people engaged in actions } \\
\text { whose primary intent is to enhance health". }{ }^{19} \text { Hunter, Dal Poz and Kunjumen } \\
\text { describe the health workforce as a key building block of health systems, }{ }^{20} \text { with } \\
\text { health workforce strengthening identified as a priority for action for } \\
\text { strengthening those systems in global policy directions. }{ }^{5}\end{array}$ \\
\hline $\begin{array}{l}\text { Regulatory } \\
\text { system } \\
\text { capacity }\end{array}$ & $\begin{array}{l}\text { The action or process of officially recognizing an individual practitioner or an } \\
\text { institution as having a particular status or being qualified to perform a particular } \\
\text { activity. Nursing and midwifery legislation and regulations provide for i) the } \\
\text { children's specialist nursing role ii) category of professional registration for } \\
\text { children's nurses iii) defined Scope of practice, iv) licensing process v) accredited } \\
\text { children's nursing training provision including curricula and institutions. }{ }^{10}\end{array}$ \\
\hline $\begin{array}{l}\text { Stakeholder } \\
\text { collaboration }\end{array}$ & $\begin{array}{l}\text { Deverka et al. }{ }^{16} \text { define stakeholders as individuals, organizations or communities } \\
\text { that have a direct interest in the process and outcomes of a project, research or } \\
\text { policy endeavor. Bi-directionality is an important component of mature } \\
\text { stakeholder collaboration. Five levels of stakeholder engagement are defined: } \\
\text { minimal awareness and interaction; consultation; engagement; participation; and } \\
\text { bi-directional collaboration among stakeholders enabling opportunities for } \\
\text { reciprocal learning and shared decision-making. The ultimate goal of the process } \\
\text { is partnership between stakeholders. }\end{array}$ \\
\hline
\end{tabular}

In addition to the four single-stakeholder domains of the education system, clinical system, human resources for health $(\mathrm{HRH})$, and regulatory system, we defined a fifth multi-stakeholder domain which we called stakeholder collaboration.

\section{vi) Characterisation of different levels of capability}

The processes, practices and behaviours identified through review of programme documentation and other literature were allocated to the relevant stakeholder domains. Steps within the domains of human resources and the regulatory system were both readily summarised since we were working from the existing Capability Maturity Models for health information systems ${ }^{8}$ and regulatory system capacity ${ }^{10}$. 
Similarly, classification of levels of stakeholder engagement were developed with reference to Deverka et al. $^{16}$

For each aspect of capability, a statement describing full capability maturity was developed first and recorded under Level 5, followed by statements describing capability at the other levels. After developing the initial statements under each level, the horizontal and vertical alignment of the statements was reviewed to achieve consistency with regard to chronology and sequencing of interdependent events and conditions.

\section{v) Consultation with stakeholders}

The resulting draft model was presented to leading practitioners from each stakeholder domain for comment and input before finalisation. Consultation was via three routes. Firstly, the draft model was presented to 30 participants representing 11 schools of nursing across nine African countries at the Children's Nurse Educator Forum in September 2020 via an online video presentation and brief facilitated discussion. Secondly, forum participants as well as additional consultees from each stakeholder domain were provided with a copy of the draft model and invited by email to contribute to the consultation through a structured questionnaire using Google Forms. Thirdly, two online video call sessions were held which were open to any consultees who preferred to offer their feedback through dialogue with the researcher. These sessions were structured to explore the same questions as the online questionnaire.

Consultees were asked to state, based on their own experience, the three most important conditions that need to be in place to establish a new children's nursing training programme. They were then guided to assess the extent to which these conditions were included in the draft model. Consultees were asked to comment on how closely the organisational processes, practices and behaviours described matched the consultee's own health system. Finally, consultees were asked to provide suggestions for improving the relevance, applicability or understandability of the information presented.

\section{Results}

The process described above resulted in a set of five step-wise progressions for each of the five domains (see Figure 1) and the creation of the Capability Maturity Model presented in Figure 2. Key outcomes and results of the process of development are reported below.

The review of programme documentation and reflection on experiential knowledge determined that this capability maturity model would need to describe multidimensional processes, practices and behaviours at both individual and organisational tiers. Five levels of process maturity were identified, and these were described in the form of macro-descriptions as shown in Figure 1.

The Capability Maturity Model presented in Figure 2 describes the five different levels of capability for each of the domains and stakeholder functions. There was some debate around the extent to which statements should represent the ideal vs the likely reality. For example, the statement 'A new in-country 
training programme fully aligned with local needs and resources is accredited' was originally included under the macro-descriptor for Level 3 . This was changed to 'A new in-country training programme ... with explicit reference to local population needs and resources'. This change was decided on to signal a difference from the fully mature capability described at Level 5 , recognizing that after initial work to develop a programme informed by local needs and resources, collaborative review and refinement would be required to achieve full alignment.

Some of the processes represented were found to be iterative. For example, developing the capacity to refine the curriculum to be contextually specific, or the development of educator skills to deliver active learning, both occur iteratively over the course of Levels 3, 4 and 5. There was only one domain (education systems) for which sub-domains were required. The additional level of detail for this domain is consistent with the core focus of this Capability Maturity Model, which concerns the capacity to establish a new training programme, rather than wider system capacity.

Stakeholder consultation successfully engaged 36 individuals in the process of development (30 individuals through the Children's Nursing Educator Forum meeting, and a further 6 individuals subsequently). Seventeen individuals provided detailed comments and suggestions, with eight of these completing the online questionnaire and nine participating in the video calls. Individuals who provided detailed comments and suggestions were from Namibia, Rwanda, South Africa, Zambia and Zimbabwe, working within the stakeholder domains of education, clinical or regulatory systems, and human resources for health. There were no inconsistencies in the responses received, and all suggestions were incorporated into a revised version of the Capability Maturity Model, including revisions to the macrodescriptors. Substantive revisions made as a result of feedback received included strengthening the importance given to securing a mandate from the ministry of education, and providing a clearer description of the resourcing required to start up a new programme. All consultees confirmed that the draft Capability Maturity Model was a helpful way of describing the process of establishing new children's nursing training programmes, and that the organisational processes, practices and behaviours described matched their own health system sufficiently closely for the model to be easily applicable.

\section{Discussion}

The Capability Maturity Model that was developed defines five domains that are critical to establishing nursing education programmes, and describes a navigable pathway from first steps to sustainable programme maturity. The model makes visible the very wide range of regulatory and associated processes involved in establishing a new training programme, including educational standards, quality assurance, scopes of practice, and systems for licensing and registering specialist children's nurses. In doing this, the model achieves one of the chief benefits of the CMM approach, by making the responsibilities of stakeholders explicit and providing a supportive framework for collaboration. ${ }^{8}$ Stakeholders are therefore able to use the model as a roadmap, to identify where they are and what actions and resources are needed to reach their shared destination. 
In highlighting the resources needed to make progress and build the desired system capacity we have tried to adhere to the values and principles of an asset-based approach ${ }^{13}$ striking a balance between steps that will meet urgent needs in the short-term and steps that will nurture the strengths and resources of individuals and organisations connected to children's nursing over the longer term. We have also intentionally included objectively identifiable actions, behaviours and processes designed to facilitate the

'everyday doing' of education 22 in ways that facilitate the development of occupational consciousness as a deliberate strategy in educational practice development uniquely suited to post-colonial and postapartheid African societies.

The process that was followed and the Capability Maturity Model that resulted have both strengths and limitations. The model benefits from the application of considerable experiential knowledge from multiple individuals representing a comprehensive set of stakeholder groups, combined with information gained from published research and other documentation. We anticipate that this will have supported accuracy. The model does not describe all of the functions of the many organisations and stakeholders represented, and instead focuses on a limited set of functions critical to the establishment of new children's nursing training programmes. HRH capacity and regulatory capacity are comprehensively addressed by existing CMMs. ${ }^{10,8}$ Although consultation sought to maximise relevance and suitability for application, the model has not yet been implemented. The model is specific to children's nursing training in southern and eastern Africa. We expect that it could be applied to other nursing and potentially other health professionals specialisms and other geographies with necessary adaptation to local contexts, which stakeholders could carry out following the process we have described.

We intend to work with members of the Children's Nursing Educators Forum and wider stakeholders in southern and eastern Africa to implement the model in at least three countries during 2021-2022. This process will be evaluated and any refinements made, with an up-to-date version of the model and guidance on implementation maintained online through the Open Science Framework at https://osf.io/tegx7/

Stakeholders wishing to apply the model to assess their state of Capability Maturity should note the intended application, which is that all conditions described in a step need to be met in full before that step can be considered completed.

\section{Conclusions}

The steps involved in establishing new children's nursing training programmes must be considered as part of a comprehensive set of processes, practices and behaviours encompassing specialist nursing regulation and nursing education as well as wider human resources for health functions. These systems need to operate hand-in-hand as part of an integrated and strategic response to specialist nursing workforce development.

\section{List Of Abbreviations}




\section{Declarations}

Ethics approval and consent to participate This project did not involve human subjects or interventions. Ethical approval was not required.

Consent for publication Not applicable

Availability of data and materials All relevant data and materials are presented in the manuscript. an upto-date version of the model and guidance on implementation maintained online at

https://osf.io/tegx7/

Competing interests The authors declare no competing interests.

Funding The Harry Crossley Children's Nursing Development Unit receives funding and philanthropic support from the Vitol Foundation. The Vitol Foundation provides general programmatic support and had no role in the design of the study and collection, analysis, and interpretation of data.

Authors' contributions $\mathrm{MC}$ and NN conceptualised and developed the model. NN produced the first draft of the manuscript and $\mathrm{MC}$ revised it for publication.

Acknowledgements The development process was facilitated by a monitoring and evaluation professional external to the programme, Robin Pocock. We are grateful to all the members of the Children's Nursing Educators Forum for their engagement in this process. We particularly recognise the provision of detailed feedback from: Chabulembwa Chitimbwa, Ireen Chisanga, Priscilla Kalunga, Sibeso Kamwi, Mitchell Lyowah Bulaya and Alice Berrice Chitalu Mwango (School of Paediatrics and Child Health, Arthur Davison Hospital, Zambia); Aaron Banda (Clinton Health Access Initiative, Zambia); Cynthia Spies (Free State University, South Africa); Eric Chisupa (Lusaka Schools of Nursing, Zambia); Yeovonnie Chauraya (National University of Science and Technology, Zimbabwe); Tara Hilton, Angela Leonard and Lee-Ann White (University of Cape Town, South Africa); Seugnette Rossouw (University of Pretoria, South Africa); Pamela Meharry (University of Rwanda, Kigali and Department of Women's, Children's and Family Health Services, University of Illinois, Chicago, USA); and Beatrix Callard (Windhoek Central Hospital, Namibia). Children's nursing education programmes at the University of Cape Town are offered collaboratively under the governance of the Division of Nursing and Midwifery as the accredited School of Nursing.

\section{References}

1. World Health Organization. State of the world's nursing 2020: investing in education, jobs and leadership. WHO: Geneva; 2020. 
2. International Council of Nurses. Schober M, Lehwaldt D, Rogers M, Steinke M, Turale S, Pulcini J, Roussel J, and Stewart D. 2020. Guidelines on advanced practice nursing. Geneva. 16 April 2020. Available from https://www.icn.ch/news/icn-launches-new-advanced-practice-nursing-guidelinesand-calls-increased-recognition-and Accessed May 11th 2020.

3. North N, Shung-King M, Coetzee M. The children's nursing workforce in Kenya, Malawi, Uganda, South Africa and Zambia: generating an initial indication of the extent of the workforce and training activity. Human Resources for Health. 2019 Dec 1;17(1):30.

4. Global Health Workforce Alliance. Scaling Up, Saving Lives: Task Force For Scaling Up Education and Training for Health Workers. Geneva: World Health Organization Press; 2008.

5. World Health Organization. 2007. Everybody's business - strengthening health systems to improve health outcomes: WHO's framework for action. WHO Document Production Services: Geneva. ISBN 9789241596077

6. Hammond WE, Bailey C, Boucher P, Spohr M, \& Whitekar P. (2010). Connecting information to improve health. Health Affairs, 29 (2), 284-288. Retrieved from

https://www.ncbi.nlm.nih.gov/pubmed/20348075

7. Carvalho, J.V., Rocha, A., \& Abreu, A. (2016). Maturity models of healthcare information systems and technologies: A literature review. Journal of Medical Systems, 40 (6), 131. Retrieved from https://www.ncbi.nlm. nih.gov/pubmed/27083575

8. Measure Evaluation. 2019. Health Information Systems Interoperability Maturity Toolkit: Users' Guide. Version 1.0 (updated January 2019). United States Agency for International Development and the Health Data Collaborative. Available from https://www.measureevaluation.org/resources/publications/tl-17-03a Accessed April 12th 2020

9. Measure Evaluation. 2018. Global Digital Health Resources and Maturity Models: A Summary. Available from https://www.measureevaluation.org/resources/publications/fs-18-305/ Accessed February 10th 2019.

10. McCarthy, C. F., Kelley, M. A., Verani, A. R., Louis, M. E. S., \& Riley, P. L. (2014). Development of a framework to measure health profession regulation strengthening. Evaluation and program planning, $46,17-24$.

11. Dynes M, Tison L, Johnson C, Verani A, Zuber A, Riley PL. Regulatory advances in 11 sub-saharan countries in year 3 of the African Health Profession Regulatory Collaborative for Nurses and Midwives (ARC). Journal of the Association of Nurses in AIDS Care. 2016 May 1;27(3):285-96.

12. Ruthe \& North. Developing a specialist children's nursing workforce in sub-Saharan Africa: a descriptive programme evaluation. BMC Nursing (Accepted November 2020). In press.

13. Glasgow Centre for Population Health. Putting asset-based approaches into practice: identification, mobilisation and measurement of assets. July 2012. Glasgow. Available at https://www.gcph.co.uk/assets/0000/3433/GCPHCS10forweb_1_.pdf Accessed December 19th 2019 
14. Coetzee M, McKerrow N, Chimwaza A, Molyneux E, North N, Sieberhagen S. Building paediatric nurse training capacity for Africa, in Africa. The Lancet Global Health.

15. 2016;4(7):e449-e50.

16. Coetzee M. (2014). Re-envisioning paediatric nurse training in a re-engineered health care system. Curationis. 37(2): 1-8.

17. Deverka PA, Lavallee DC, Desai PJ, Esmail LC, Ramsey SD, Veenstra DL, et al. Stakeholder participation in comparative effectiveness research: defining a framework for effective engagement. J Comp Eff Res. 2012;1(2):181-94.

18. The Glossary of Education Reform. https://www.edglossary.org/capacity/ Accessed July 10th 2020.

19. World Health Organization. Health Systems. https://www.who.int/healthsystems/about/en/ Accessed July 10th 2020.

20. World Health Organization. The world health report 2006: working together for health. World Health Organization; 2006 Mar 23.

21. Hunter D, Dal Poz MR, Kunjumen T. Boundaries of the health workforce: definition and classification of health workers. Handbook on monitoring and evaluation of human resources for health with special applications for low-and middle-income countries. 2009:13-22.

22. Ramugondo EL. Occupational consciousness. Journal of Occupational Science. 2015 Oct 2;22(4):488-501.

\section{Figures}




\begin{tabular}{|c|c|}
\hline Level & Description \\
\hline $\begin{array}{l}\text { Level 1: } \\
\text { Nascent }\end{array}$ & $\begin{array}{l}\text { General nurse and midwifery training is securely established, but children's nursing training } \\
\text { programmes and trained children's nurses are absent. } \\
\text { Actions towards establishing training programmes may be happening by chance, or represent } \\
\text { isolated, ad hoc, or individual heroic efforts. } \\
\text { Initial advocacy and proposals might be in process. }\end{array}$ \\
\hline $\begin{array}{l}\text { Level 2: } \\
\text { Emerging }\end{array}$ & $\begin{array}{l}\text { The systems, processes and resources for establishing training programmes are defined and } \\
\text { increasingly functional. } \\
\text { A new in-country training programme aligned with local needs and resources is accredited } \\
\text { through institutional and national regulatory routes. } \\
\text { Development of core specialist clinical and educator workforce required to deliver the new } \\
\text { programme through staged release. } \\
\text { Stakeholders begin to exchange available workforce and training data, and identify additional } \\
\text { data needs. }\end{array}$ \\
\hline $\begin{array}{l}\text { Level 3: } \\
\text { Established }\end{array}$ & $\begin{array}{l}\text { The systems, processes and resources for establishing training programmes are beginning to be } \\
\text { defined, but some important components may be incomplete. } \\
\text { There is an in-principle agreement by the Ministry of Health that there is a need for a training } \\
\text { programme. }\end{array}$ \\
\hline $\begin{array}{l}\text { Level 4: } \\
\text { Institutionalised }\end{array}$ & $\begin{array}{l}\text { Well-established framework for implementation as part of strongly aligned national and regional } \\
\text { strategies, policies, processes and resourcing for child health and workforce development. } \\
\text { Training activity is directed by a shared strategy which is informed by accurate data about the } \\
\text { children's nursing workforce, clinical service needs, and training activity. }\end{array}$ \\
\hline $\begin{array}{l}\text { Level 5: } \\
\text { Optimised }\end{array}$ & $\begin{array}{l}\text { The systems, processes and resources for establishing education programmes are regularly } \\
\text { reviewed and opportunities for learning and improvement are taken. } \\
\text { Stakeholder collaboration is mature, with well-established interpersonal and inter-organisational } \\
\text { relationships. } \\
\text { Education institutions and clinical services can deliver and absorb trainees, with routine recording } \\
\text { of specialist qualifications and clear employment pathways. } \\
\text { The contribution of children's specialist nurses to the health system is visible. }\end{array}$ \\
\hline
\end{tabular}

\section{Figure 1}

Step-wise domain progression from nascent to established 

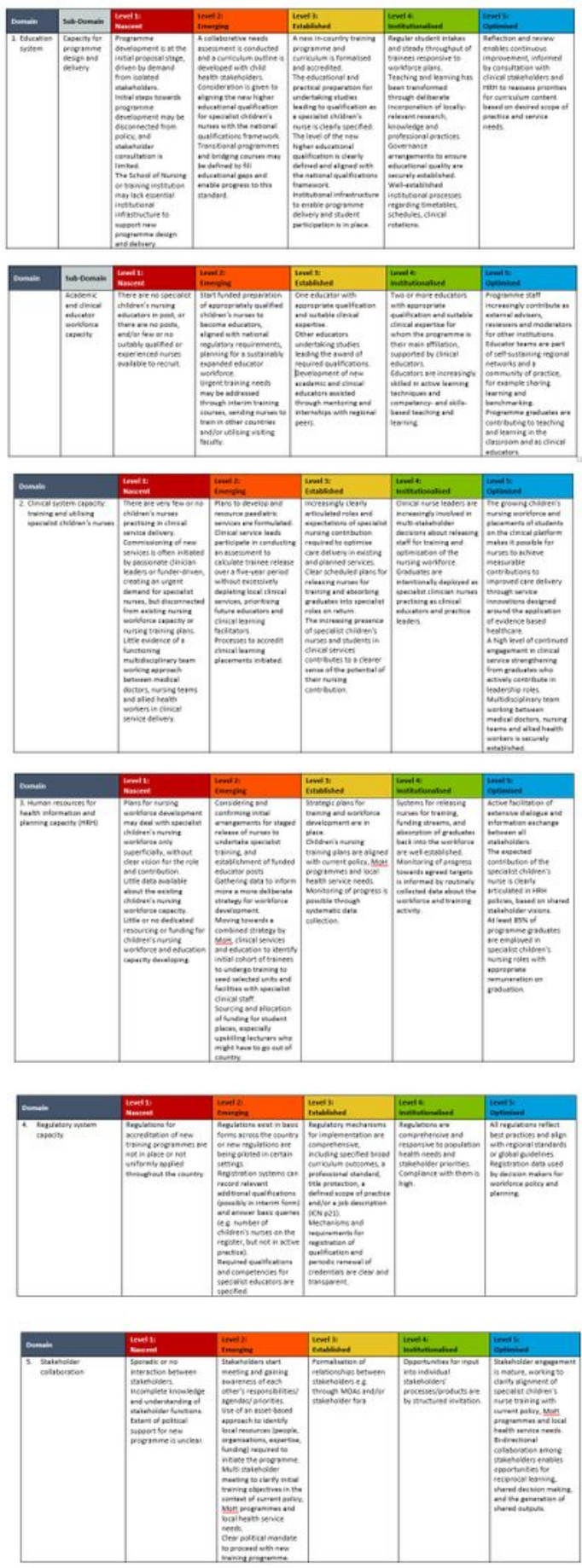

Figure 2

A Capability Maturity Model for the Establishment of Children's Nursing Training Programmes 